\title{
PENYULUHAN PENGGUNAAN MEDIA PEMBELAJARAN UNTUK PENGEMBANGAN MOTORIK HALUS ANAK PADAGURU-GURU PAUD GUGUS MAWAR MERAH
}

\author{
COUNSELING ON THE USE OF LEARNING MEDIA FOR CHILDREN'S FINE \\ MOTORIC DEVELOPMENT TO EARLY CHILDHOOD TEACHERS IN MAWAR \\ MERAH CLUSTERS
}

\author{
${ }^{1)}$ Sri Saparahayuningsih, ${ }^{2)}$ Zahratul Qalbi, ${ }^{3)}$ Badeni \\ ${ }^{1,2)}$ Prodi Pendidikan Guru PAUD FKIP UNIB, ${ }^{3)}$ Prodi Doktor Pendidikan FKIP UNIB) \\ *saparahayuningsih@unib.ac.id
}

\begin{abstract}
ABSTRAK
Tujuan pengabdian kepada masyarakat ini adalah memberi penyuluhan kepada para guru Pendidikan Anak Usia Dini Gugus Mawar Merah Kotamadya Bengkulu tentang penggunaan media pembelajaran untuk mengembangkan motorik halus anak usia dini. Anak yang kurang memiliki keterampilan motorik halusnya, mereka akan mengalami kesulitan menampilkan akademiknya dan tugas-tugas kehidupan sehari-hari. Guru Pendidikan Anak Usia Dini memiliki tugas untuk mengembangkan keterampilan motorik anak melalui pembelajaran. Agar materi pembelajaran pengembangan motorik halus dapat diterima oleh anak dengan baik diperlukan media pembelajaran. Keterbatasan pengalaman dan motivasi belajar anak dapat diatasi dan dirangsang melalui penggunaan media pembelajaran. Berdasarkan Hasil survey kami terhadap para guru diperoleh informasi bahwa para guru kurang mengetahui penggunaan media untuk pengembangan motorik halus anak. Melihat hal itu kami tim Dosen Pendidikan Anak Usia Dini Universitas Bengkulu merasa penting untuk memberikan pelatihan kepada mereka tentang penggunaan media dalam mengembangkan motorik halus anak. Selama pelatihan para peserta aktif mengikuti seluruh kegiatan dan antusias dalam mengerjakan latihan- latihan pengembangan media. Sebagai hasil kegiatan pelatihan, rara-rata para guru Gugus Mawar Merah Kotamadya Bengkulu meningkat sangat baik dalam menggunakan media pembelajaran untuk mengembangkan motorik halus anak usia dini.
\end{abstract}

Kata Kunci: Media Pembelajaran, Motorik Halus

\section{ABSTRACT}

The aim of this community service is to provide counseling to the teachers of the Bengkulu City Early Childhood Education Mawar Merah Clusters regarding the use of instructional media to develop fine motor skills for early childhood. Children who lack fine motor skills, they will have difficulty performing academic and daily life tasks. Early Childhood Education Teachers have a duty to develop children's motor skills through learning. In order for fine motoric development learning materials to be accepted by children properly, learning media are needed. Limitations of children's learning experiences and motivation can be overcome and stimulated through the use of learning media. Based on the results of our survey of teachers, it is found that teachers do not know the use of media for children's fine motoric development. Seeing this, our team of Lecturers of Childhood Education at Bengkulu University felt compelled to provide training to them on the use of media in developing children's fine motor skills. During the training, the participants actively participated in all activities and were enthusiastic in carrying out media development exercises. As a result of the training activities, the average Bengkulu City Mawar Merah Cluster teachers improved greatly in using learning media to develop fine motor skills for early childhood.

Keywords: Learning Media, Fine Motoric.

Diterima : 29-05-2021 Disetujui : 01-06-2021 Dipublikasikan: 30-06-2021 


\section{PENDAHULUAN}

Usia dini merupakan usia yang sangat menentukan bagi pertumbuhan dan perkembangan anak selanjutnya. Sebagaimana yang dikemukakan Yamin dan Sanan (2010:5) bahwa usia lahir sampai dengan memasuki pendidikan dasar merupakan masa keemasan sekaligus masa kritis dalam tahapan kehidupan manusia, yang akan menentukan kehidupan selanjutnya. Masa ini merupakan masa yang tepat untuk meletakkan dasar-dasar pengembangan fisik, bahasa, sosialemosional, konsep diri, seni, moral dan agama. Kemudian Bloom (dalam Wiyani, 2014:28), mengemukakan bahwa pada usia dini perkembangan intelektual sangat pesat pada awal tahun-tahun awal kehidupan anak. Sekitar 50\% kecerdasan orang dewasa sudah terjadi sejak usia 4 tahun. Lebih lanjut Bloom juga mengatakan bahwa 4 tahun pertama merupakan kurun waktu yang sangat peka terhadap kaya miskinnnya lingkungan akan stimulasi. Pendapat ini didukung oleh pendapat Motessori (dalam Wiyani, 2014:29) bahwa usia emas merupakan masa dimana anak mulai peka untuk menerima berbagai stimulasi dan uapaya pendidikan dari orang dewasa dan lingkungannya baik disengaja maupun tidak disengaja. Pada masa peka ini terjadi pematangan fungsi-fungsi fisik dan psikis sehingga anak siap merespons dan mewujudkan semua tugas-tugas perkembangan yang diharapkan muncul pada pola perilakunya sehari-hari.

Pendidikan Anak Usia Dini (PAUD) merupakan salah satu lembaga yang mempunyai tanggung jawab untuk mengembangan potensi pada masa usia dini tersebut. Sebagaimana yang dikemukakan Wiyani (2014:32) bahwa tujuan penyelenggaraan PAUD adalah untuk mengembangkan semua aspek perkembangan anak usia dini, meliputi pertumbuhan fisik (keterampilan motorik kasar dan halus) kognitif, bahasa, sosial-emosi, moral dan agama. Demikian juga Susanto (2017:14), menyebutkan bahwa PAUD merupakan salah satu bentuk penyelenggaraan pendidikan yang menitik beratkan pada peletakan dasar ke arah petumbuhan sesuai dengan keunikan dan tahap-tahap perkembangan sesuai dengan usia kelompok usia yang dilalui oleh anak. Dalam Permendikbud Nomor 37 tahun 2014, Pasal 1 ayat 2 tercantum bahwa Standar tingkat pencapaian perkembangan

anak usia dini (STTPA) yang merupakan kreteria tentang kemampuan yang dicapai anak pada seluruh aspek perkembangan dan pertumbuhan mencakup aspek perkembangan dan pertumbuhan yang mencakup aspek nilai agama dan moral, fisik-motorik, kognitif, bahasa, sosial emosional, dan seni.

$$
\text { Aspek fisik-motorik adalah }
$$

kemampuan gerak, baik gerak kasar maupun gerak halus. Bagi pertumbuhan fisik-motorik, anak usia 4-6 tahun masih memerlukan aktivitas yang banyak. Wulan (2011:28) mengatakan bahwa memasuki usia 5-7 tahun, sebagian besar yang dialami anak-anak adalah mengasah kembali keterampilan motorik yang sudah dikenal sampai tahap penguasaan. Beberapa keterampilan motorik tersebut adalah menulis, menggambar dan gerakan-gerakan yang dilakukan saat bermain dan berolah raga.

Ada beberapa permasalahan anak usia dini yang terkait dengan motorik halus. Masalah-masalah tersebut adalah pertama, anak belum bisa menggambar bentuk bermakna dan yang kedua, anak belum bisa mewarnai dengan rapi (Wiyani, 2014:52).

Ketika anak kurang terampil motorik halusnya, anak akan mengalami kesulitan menampilkan akademiknya. Sebagaimmana pendapat juga Kid Sense Child Development Corporation Pty Ltd (2018) "When a child has fine motor skill difficulties, they might also have difficulties with, showing academic ability: being verbally very skilled but having difficulty showing this on paper (i.e. writing, drawing or colouring)".

Guru PAUD memiliki tugas untuk mengembangkan keterampilan motorik anak melalui pembelajaran. Agar materi untuk pengembangan motorik halus dapat diterima anak dengan baik diperlukan media pembelajaran. Media pembelajaran dapat mengatasi keterbatasan pengalaman yang dimiliki oleh para peserta didik (https://akhmadsudrajat.wordpress.com/2008/ 01/12/konsep-media-pembelajaran), dan dapat merangsang dan memotivasi siswa untuk belajar (Jamaluddin M, 2018).

Kemampuan yang harus dikuasai oleh guru selain mampu memilih media 
pembelajaran secara tepat adalah kemampuan dalam mengembangkan media pembelajaran. Kegiatan pengembangan ini banyak terkait dengan proses pembuatan media yang dilakukan secara sistematis dari mulai tahap perancangan/desain, produksi media, dan penggunaan.

Modul sebagai salah satu bentuk media cetak dalam pembelajaran yang dikemas secara utuh dan sistematis, didalamnya memuat seperangkat pengalaman belajar yang terencana dan didesain untuk membantu peserta didik menguasai tujuan belajar yang spesifik. Modul minimal memuat tujuan pembelajaran, materi/substansi belajar, dan evaluasi. Adapun desain media pembelajaran untuk pengembangan motorik halus anak usia dini yang digunakan dalam pengabdian kepada masyarakat adalah sebagai berikut:

\begin{tabular}{|l|l|}
\hline Nama media & Pengembangan motorik halus \\
\hline Sasaran & Anak kelompok B PAUD \\
\hline $\begin{array}{l}\text { Kemampuan } \\
\text { yang } \\
\text { dikembangkan }\end{array}$ & Motorik halus anak \\
\hline $\begin{array}{l}\text { Bahan dan } \\
\text { Alat }\end{array}$ & $\begin{array}{l}\text { Kertas (origami/bekas), lem, pewarna, gunting, } \\
\text { lidi, gelas plastik dan lain-lain }\end{array}$ \\
\hline Cara membuat & Langkah-langkahnya \\
\hline $\begin{array}{l}\text { Cara } \\
\text { menggunakan }\end{array}$ & $\begin{array}{l}\text { Sebutkan tema, mulai dari bercerita (untuk } \\
\text { mengisi kognitif anak), praktek membuat } \\
\text { bentuk (motorik halus), memajang (motorik } \\
\text { halus, kreatvitas) }\end{array}$ \\
\hline
\end{tabular}

Permasalahannya adalah banyak guru-guru PAUD di Gugus Merah Bengkulu yang belum mengetahui penggunaan media untuk pengembangan motorik halus anak. Oleh karena itu dalam pengabdian masyarakat ini akan dilakukan penyuluhan tentang penggunaan media pembelajaran untuk mengembangkan motorik halus anak usia dini.

\section{METODE}

Khalayak sasaran pengabdian kepada masyarakat ini adalah seluruh guru-guru PAUD Gugus Merah Bengkulu Kota. Tujuannya adalah memberi agar guru-guru PAUD memiliki wawasan pengetahuan dan keterampilan untuk penggunaan media pembelajaran pengembangan motorik halus anak usia dini.
Adapun cara pelaksanaan kegiatan ini melalui: 1. Survey lapangan, 2. Pelatihan, 3. Evaluasi, dan 4 Refleksi.

Survey lapangan dilakukan untuk mengetahui tempat lokasi pengabdian masyarakat dan mengetahui jumlah guruguru yang dapat mengikuti kegiatan saat pelatihan penggunaan media pembelajaran. Mengingat pelatihan ini dilakukan saat masih pandemi, maka waktu survey ini mendata kemungkinan guru-guru yang bersedia mengikuti saat pelatihan. Selain itu saat survey juga dilakukan untuk mengetahui permasalahan-permasalahan yang dihadapi oleh guru dalam meningkatkan kemampuan motorik halus anak.

Tahap kedua adalah tahap pelatihan. Sebelum melakukan pelatihan tim merancang media pembelajaran pengembangan motorik halus anak. Setelah itu hasil rancangan diuji coba bersama tim pengabdian masyarakat, setelah itu baru dicetak menjadi modul pelatihan media pembelajaran pengembangan mototik halus anak usia dini.

Berdasarkan konsep desain media dan survey lapangan maka dapat disusun buku modul pelatihan penggunaan media pembelajaran pengembangan motorik halus. Saat pelaksanaan pelatihan metode yang digunakan untuk melaksanakan pengabdian kepada masyarakat ini adalah penyuluhan. Metode penyuluhan adalah cara yang sistematis untuk menyampaikan pesan agar dapat terjadi perubahan sehingga sasaran tahu, mau dan mampu dalam menerapkan inovasi baru. Jenis metode penyuluhan yang digunakan adalah metode penyuluhan langsung dengan ceramah, tanya jawab, demonstrasi dan pemberian tugas latihan.

Tahap ketiga adalah evaluasi. Pada tahap ini dilakukan evaluasi atas hasil yang telah dicapai oleh peserta pelatihan. Masukan dan perbaikan lebih lanjut dapat dilakukan pada tahap ini. Evaluasi dilakukan dengan cara memberikan instrumen tentang pengetahuan dan keterampilan yang diperoleh selama pelatihan yaitu bagaimana kemampuan dan keterampilan guru-guru dalam menggunakan media pembelajaran pengembangan motorik halus. 


\section{Tahap keempat adalah refleksi.} Berdasarkan data evaluasi dan tanya jawab dengan peserta kemudian dianalisis untuk mengetahui kelebihan dan kelemahan dan selanjutnya dilakukan perbaikan. Indikator ketercapaian tujuan pengabdian kepada masyarakat ini adalah bahwa $75 \%$ guru-guru sudah memahami penggunaan media pembelajaran pengembangan motorik halus anak usia dini.

\section{HASIL DAN PEMBAHASAN Hasil}

Kegiatan pengabdian kepada masyarakat tentang penggunaan media pembelajaran untuk pengembangan motorik halus anak pada guru-guru PAUD segugus Mawar bertempat di TK Dharma Wanita Propinsi Bengkulu.

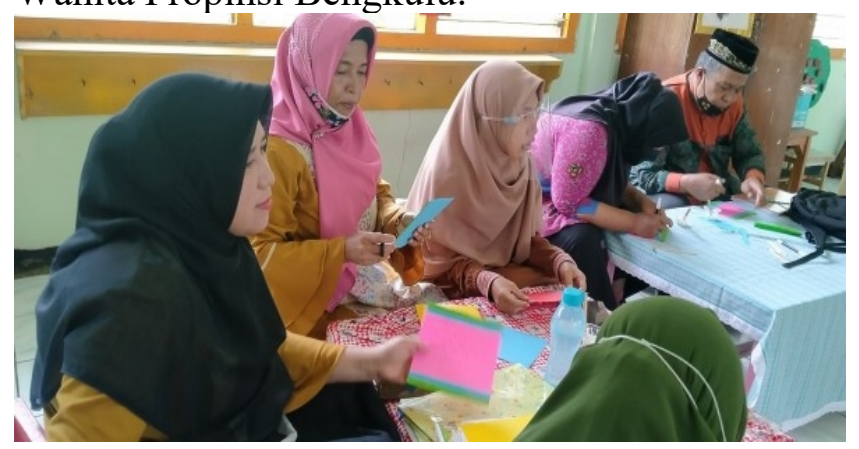

Penyuluhan ini diikuti oleh 21 orang guru yang aktif dari awal sampai akhir kegiatan.

Kegiatan ini dimulai dengan pemberian materi tentang pentingnya perkembangan motorik halus anak usia dini, terutama yang terkait dengan tugas akademik dan tugas sehari-hari

Materi yang kedua adalah penggunaan media pembelajaran dalam menstimulasi perkembangan motorik halus anak. Kegiatan selanjutnya adalah simulasi penggunaan media pembelajaran untuk mengembangkan motorik halus anak. Dalam kegiatan ini diperagakan oleh mahasiswa Prodi PG PAUD FKIP UNIB. Kegiatan terakhir adalah praktik penerapan penggunaan media pengembangan motorik halus. Dalam praktik ini guru-guru diberikan modul pelatihan. Guru dalam menggunakan media pengembangan motorik halus pada anak usia dini dimulai dengan mengisi kognitif anak terlebih dahulu dengan bercerita sesuai dengan kegiatan yang akan diberikan guru, sehingga nanti anak jika mengerjakan kegiatan dalam fikiran anak sudah ada gambaran apa yang akan dikerjakan.

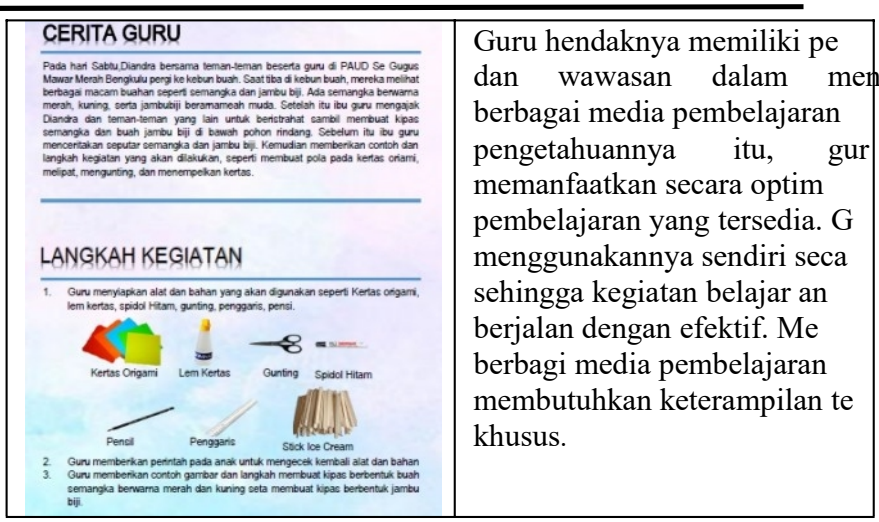

Setelah selesai melaksanakan kegiatan pengabdian kepada masyarakat kegiatan selanjutnya adalah tanya jawab dan mengisi angket untuk mengumpulkan data peserta selama mengikuti PKM.

Hasil kegiatan pengabdian kepada masyarakat tentang penggunaan media pembelajaran pengembangan motorik halus anak dapat dilihat dalam tabel sebagai berikut:

Tabel 1: Hasil PKM

\begin{tabular}{|c|c|c|c|c|}
\hline No & Aspek yang diukur & $\begin{array}{l}\text { Rata- } \\
\text { rata skor }\end{array}$ & Kategori & $\%$ \\
\hline 1 & $\begin{array}{lr}\text { Pengetahuan } & \text { yang } \\
\text { diperoleh } & \text { setelah } \\
\text { mengikuti } & \text { kegiatan } \\
\text { PKM } & \end{array}$ & 4 & SB & $100 \%$ \\
\hline 2 & $\begin{array}{lr}\text { Keterampilan } & \text { yang } \\
\text { diperoleh } & \text { peserta } \\
\text { setelah } & \text { mengikuti } \\
\text { PKM } & \end{array}$ & 4 & SB & $98,9 \%$ \\
\hline 3 & $\begin{array}{ll}\text { Antusiame } & \text { peserta } \\
\text { selama PKM }\end{array}$ & 4 & SB & $100 \%$ \\
\hline 4 & $\begin{array}{lr}\text { Partisipasi } & \text { peserta } \\
\text { dalam mengikuti } & \text { megiatan PKM }\end{array}$ & 4 & SB & $100 \%$ \\
\hline 5 & $\begin{array}{l}\text { Tingkat pemahaman } \\
\text { peserta setelah } \\
\text { mengikuti PKM }\end{array}$ & 4 & SB & $100 \%$ \\
\hline
\end{tabular}

Skor $4=$ Sangat Baik $=$ SB

Skor $3=$ Baik $\quad=\mathrm{B}$

Skor $2=$ Kurang $=\mathrm{K}$

Skor $1=$ Sangat Kurang $=$ SK

\section{Pembahasan}

Kegiatan pengabdian kepada masyarakat tentang penyuluhan penggunaan media pembelajaran untuk pengembangan motorik halus anak usia dini bagi guru-guru Gugus Mawar Merah Kota Bengkulu, hasilnya rata-rata pengetahuan dan keterampilan adalah sangat baik. Selama mengikuti kegiatan pengabdian guru-guru dapat memahami materi dan
ABDI PAUD

Volume 2 No 1 Tahun 2021 https://ejournal.unib.ac.id/index.php/abdipaud/index 
mengimplementasikan dalam praktik sebagai guru PAUD. Jadi guru-guru memiliki baik pengetahuan, pemahaman dan keterampilannya tentang penggunaan media pengembangan motorik halus anak sangat baik. Hal ini memang seharusnya dimiliki oleh setiap guru PAUD sebagai kompetensi yaitu kompetensi pedagogis. Kompetensi pedagogis, mencakup kemampuan untuk dapat: (1) memahami karakteristik, kebutuhan, dan perkembangan peserta didik; (2) menguasai konsep dan prinsip pendidikan; (3) menguasai konsep, prinsip dan prosedur pengembangan kurikulum; (4) menguasai teori, prinsip, dan strategi pembelajaran; menciptakan situasi pembelajaran yang interaktif, inspiratif, menyenangkan, menantang, memotivasi pe-serta didik untuk berpartisipasi aktif, serta memberi ruang yang cukup bagi prakarsa, kreativitas, dan kemandirian; (6) menguasai konsep, prinsip, prosedur, dan strategi bimbingan belajar peserta didik; serta (7) menguasai media pembelajaran termasuk teknologi komunikasi dan informasi; (8) menguasai prinsip, alat, dan prosedur penilaian proses dan hasil belajar (Peraturan Pemerintah No. 19 Tahun 2005).

Saat menerapkan penggunaan media pembelajaran terjadi dialog bahwa sebelum anak usia dini diberi kegiatan-kegiatan untuk pengembangan motorik halus, guru memberi pengetahuan terlebih dahulu melalui bercerita. Sehingga saat melakukan kegiatan anak akan mengkaitkan pengetahuan yang diperoleh dengan kegiatan-kegiatan motorik halus anak.

Dengan dimiliki pengetahuan dan keterampilan penggunaan media pengembangan motorik halus anak, maka peningkatan kualitas pembelajaran juga akan lebih baik. Sebagaimana yang dikemukakan oleh Zaman, (2010) bahwa media dalam proses pembelajaran dapat mempertinggi proses belajar siswa dalam pembelajaran yang pada gilirannya diharapkan dapat mempertinggi hasil belajar yang dicapainya. Berbagai penelitian yang dilakukan terhadap penggunaan media dalam pembelajaran sampai pada kesimpulan, bahwa proses dan hasil belajar pada siswa menunjukkan perbedaan yang signifikan antara pembelajaran tanpa media dengan pembelajaran menggunakan media. Oleh karena itu penggunaan media pembelajaran sangat dianjurkan untuk mempertinggi kualitas pembelajaran.

Para peserta pengabdian ini juga menyatakan bahwa materi ini sangat berguna untuk pembelajaran dan mereka akan menerapkan dalam pembelajaran pengembangan motorik halus pada anak-anak usia dini. Sebagaimana yang dikatakan Syaodih (https://s3.amazonaws.com/ academia.edu.documents/37346159),kebutuh an anak untuk melakukan berbagai aktivitas sangat diperlukan, baik untuk pengembangan otot-otot kecil maupun otot-otot besar. Gerakan-gerak fisik ini tidak sekedar penting untuk mengembangkan keterampilan fisik saja, tetapi juga dapat berpengaruh positif terhadap penumbuhan rasa harga diri anak dan bahkan perkembangan kognisi. Keberhasilan anak dalam menguasai keterampilan-keterampilan motorik dapat membuat anak bangga akan dirinya. Demikian juga Kid Sense Child Development Corporation Pty Ltd (2018): "Fine motor skills are essential for performing everyday skills as well academic skills. Without the ability to complete these every day tasks, a child's self esteem can suffer, their academic performance is compromised and their play options are very limited. They are also unable to develop appropriate independence in 'life' skills (such as getting dressed and feeding themselves) which in turn has social implications not only within the family but also within peer relationships". Keterampilan motorik halus penting untuk melakukan keterampilan sehari-hari dan keterampilan akademik. Tanpa kemampuan menyelesaikan tugas sehari-hari, harga diri anak akan rendah dan kinerja akademiknya akan terganggu.

Kegiatan pengabdian kepada masyarakat ini dapat berjalan dengan lancar dan sesuai dengan yang direncanakan. Faktor Pendukung keberhasilan kegiatan ini adalah kerjasama dengan guru mitra yang sangat baik dan juga karena materi pengabdian ini dibutuhkan oleh para guru mitra. Faktor kedua adalah antusiasme para peserta yang dibuktikan dengan keseriusan dalam dalam mengikuti kegiatan mulai dari awal, sampai 
Sri Saparahayuningsih, Zahratul Qalbi, Badeni

Penyuluhan Penggunaan Media Pembelajaran Untuk Pengembangan Motorik Halus Anak Pada guru-Guru Paud

kegiatan mempraktekan pembuatan media dan sampai acara penutupan. Faktor ketiga, keberhasilan kegiatan ini karena adanya tim PKM yang solid.

\section{SIMPULAN}

Dari kegiatan pengabdian masyarakat tentang penggunaan media pengembangan motorik halus anak usia dini oleh guru-guru PAUD Gugus Mawar Merah dapat disimpulkan bahwa rata-rata guru-guru setelah diberi penyuluhan, kemampuan dan keterampilannya dalam menggunakan media pengembangan motorik halus anak sangat baik. Antusias peserta sangat baik dalam mengikuti kegiatan hingga tuntas disertai dengan aktivitas dalam mempraktekkan media

\section{UCAPAN TERIMAKASIH}

a. Pimpinan Fakultas Keguruan dan ilmu Pendidikan Universitas Bengkulu yang telah mendanai pelaksanaan kegiatan pengabdian kepada masyarakat ini.

b. Ketua PAUD Gugus Mawar Merah yang telah menjadi mitra dalam pelaksanaan kegiatan pengabdian kepada masyarakat.

c. Kepala TK Dharma Wanita Propinsi Bengkulu, yang telah menyediakan tempat untuk pelaksanaan kegiatan pengabdian kepada masyarakat ini.

d. Guru-guru se gugus mawar merah yang telah menjadi mitra dalam peaksanaan pengabdian kepada masyarakat.

e. Tim pengabdian kepada mayarakat dari mahasiswa yang telah membantu menyiapkan dan melaksanakan kegiatan pengabdian kepada masyarakat.

\section{DAFTAR PUSTAKA}

Jamaluddin M, 2018, Pelatihan Dan Pendampingan Penggunaan Media Pembelajaran Matematika Pada Orang Tua Siswa Sekolah Dasar, Jurnal Pambudi.
Peraturan Menteri Pendidikan Dan Kebudayaan Republik Indonesia Nomor 137 Tahun 2014 Tentang Standar Nasional Pendidikan Anak Usia

Peraturan Pemerintah No. 19 Tahun 2005: Standar Nasional Pendidikan

Susanto, Ahmad, (2017), Pendidikan Anak Usia Dini, Teori dan Oraktik, Penerbit Bumi Aksara: Jakarta.

Syaodih, Erna Wulan, Psikologi Perkembangan https://s3.amazonaws.com/academia. edu.documents37346159/Psikologi_Perk embangan

Wiyani, Novan Ardi, 2014, Psikologi Perkembangan Anak Usia Dini, Penerbit Gava Media, Yogyakarta.

Wulan, Ratna, (2011), Mengasah Kecerdasan Pada Anak Bayi-pra sekolah, Penerbit Pustaka Pelajar: Jogjakarta.

Yamin, Martinis dan Sanan, Jamilah Sabri, (2010), Panduan Pendidikan Anak Usia Dini, Penerbit Gaung Persada: Jakarta

https://teachmykids.co.uk/advice and tips/co louring-developing-pencil-control-or-aholding-activity

https://akhmadsudrajat.wordpress.com/2008/ $\underline{01 / 12 / \text { konsep-media-pembelajaran }}$ (Diunduh tanggal 9 Mei 2020)

Zaman, Badru dan Eliyawati,Cucu, 2010, Media Pembelajaran Anak Usia Dini, Bandung: Pendidikan Guru Pendidikan Anak Usia Dini (PG-PAUD) Jurusan Pedagogik Fakultas Ilmu Pendidikan Universitas Pendidikan Indonesia 